\title{
STUDI TENTANG KUALITAS PELAYANAN OJEK ONLINE (OJOL) GRABBIKE DAN PENGARUHNYA TERHADAP KEPUASAN PELANGGAN DI KOTA TEGAL
}

\author{
Faridah $^{1)}$, Yayat Hidayat Amir ${ }^{2)}$, Basukiyatno ${ }^{3)}$ \\ Pendidikan Ekonomi, FKIP, Universitas Pancasakti Tegal, Indonesia \\ faridahwiwoho@gmail.com
}

\begin{abstract}
The study aims to determine the quality of Grabbike online motorcycle taxi service and its effect on customer satisfaction in the Tegal City area. The quantitative approach is used as a source of data processing so that the results are presented. The study population was GrabBike online motorcycle taxi (OJOL) customers in Tegal City for one week, 1000 customers. This research used incidental sampling technique in sampling. Determination of the number of samples using the Slovin formula. From the total population of 1000 obtained a sample of 100 customers as respondents. Data collection uses observation methods, questionnaires, and documentation. The research instrument was in the form of observation sheets and questionnaires with 22 items of statements that had been tested for validity and reliability. Datalysis was analyzed with linear regression. The results showed that the quality of service had a positive and significant effect on GrabBike online motorcycle taxi customer satisfaction as evidenced by the results of the calculation of a simple linear regression analysis of $Y=16.078+0.520 X$, with the significance of the variable service quality was 0,000 because the significance value of $0,000<0.05$ was concluded service quality has a significant effect on customer satisfaction variables on OJOL GrabBike in Tegal City, meaning Ha is accepted while HO is rejected.
\end{abstract}

Keywords: Service Quality, Customer Satisfaction

\begin{abstract}
Abstrak
Penelitian bertujuan mengetahui kualitas pelayanan ojek online Grabbike dan pengaruhnya terhadap kepuasan pelanggan yang berada di wilayah Kota Tegal. Pendekatan kuantitatif digunakan sebagai sumber pengolahan data hingga penyajian hasilnya. Populasi penelitian adalah pelanggan ojek online (OJOL) GrabBike di Kota Tegal selama satu minggu yaitu 1000 pelanggan.Penelitian ini menggunakan teknik insidental sampling dalam pengambilan sampel.Penentuan jumlah sampel menggunakan rumus Slovin. Dari banyaknya populasi sebesar 1000 diperoleh jumlah sampel sebesar 100 pelanggan sebagai responden. Pengumpulan data menggunakan metode observasi, kuesioner, dan dokumentasi. Instrumen penelitian berupa lembar observasi dan kuesioner dengan22 item pernyataan yang telah diuji validitas dan reliabilitasnya. Data dianalisis dengan regresi linear. Hasil penelitian menunjukan bahwa kualitas pelayanan berpengaruh positif dan signifikan terhadap kepuasan pelanggan ojek online (OJOL) GrabBike yang dibuktikan dengan hasil perhitungan analisis regresi linear sederhana yaitu $Y=16,078+0,520 \mathrm{X}$, dengan signifikansi variabel kualitas pelayanan adalah 0,000 karena nilai signifikansi $0,000<0,05$ disimpulkan kualitas pelayanan berpengaruh signifikan terhadap variabel kepuasan pelanggan pada OJOL GrabBike di Kota Tegal, artinya Ha diterima sedangkan H0 ditolak.
\end{abstract}

Kata Kunci: Kualitas Pelayanan, Kepuasan Pelanggan 


\section{PENDAHULUAN}

Pada Era modern sekarang ini banyak sekali mode transportasi yang beragam jenisnya dari transportasi tradisional sampai ke yang modern. Transportasi merupakan sebuah layanan jasa yang dapat membantu manusia mempermudah melaksanakan aktivitas sehari-hari baik itu masalah pekerjaan maupun hiburan. Semakin meningkatnya kebutuhan akan jasa, membuat sebagian besar aktivitas manusia tidak lepas dari adanya jasa transportasi. Dengan perkembangan IPTEK manusia semakin kreatif dan inovatif dalam menciptakan bisnis baru yaitu bisnis dibidang transportasi jasa yang cara pemesanannya melalui aplikasi telepon android, dari aplikasi tersebut dapat digunakan untuk memperoleh orderan dan lokasi tempat pemesananya segera direspon, dengan begitu pelanggan dapat memantau posisi driver yang menanggapi orderan. Salah satu transportasi jasa yang dimaksud yaitu ojek online (OJOL) grabBike. GrabBike adalah salah satu transportasi modern yang membantu manusia dalam hal transportasi darat yang lebih cepat dan praktis dengan harga terjangkau.

Ojek online (OJOL) GrabBike adalah sebuah layanan jasa untuk mempermudah aktivitas manusia dalam berbagai hal. Meskipun begitu, kadang terdapat masalah yang sulit dipecahkan. Salah satunya yaitu kualitas pelayanan driver yang terkadang tidak sesuai harapan pelanggan. Pelayanan driver, akan memeberikan pengaruh yang besar dalam mewujudkan mutu dan kualitas perusahaan. Kualitas tersebut dapat dilihat dari pemberian rating bintang dari pelanggan, dari rating bintang tersebut dapat diartikan bahwa bintang (*) artinya sangat buruk, bintang $(* *)$ artinya buruk, bintang $(* * *)$ artinya cukup, bintang $(* * * *)$ artinya baik dan yang terakhir bintang (*****) artinya sangat baik. Rating tersebut dapat berpengaruh terhadap perkembangan perusahaan dalam persaingan antara perusahaan ojek online, yang mengakibatkan pelanggan beralih ke perusahaan transportasi daring lain. Oleh karena itu perlu upaya GrabBike memebrikan pelayanan prima bagi pelanggan.

Kepuasan pelanggan merupakan perasaan senang atau kecewa dari pelanggan setelah menyandingkan apa yang pelanggan terima dengan yang mereka diharapkan. Menurut Priansa (2017:197, secara tradisional definisi puas dan tidak puas merupakan perbedaan antara harapan (expectation) dan persepsi atau kinerja yang dirasakan (perceived performance). Pelanggan yang merasa puas pada layanan yang digunakan akan menggunakan kembali layanan yang ditawarkan. Kesetiaan pelanggan akan tercipta apabila kepuasan bisa diperoleh. Kepuasan pelanggan sangat tergantung pada kualitas pelayanan yang diberikan perusahaan kepada pelanggan, dengan kepuasan akan mendorong pelanggan untuk memakai jasa tersebut. Sebaliknya jika kualitas pelayanan yang diberikan tidak sesuai ekspektasi maka pelangganakan beralih pada penyedia jasa layanan lain.

Bahwa yang terjadi pada ojek online (OJOL) GrabBike di kota Tegal berdasarkan hasil observasi yang dilakukan yaitu kualitas pelayanan yang diberikan terhadap pelanggan belum memuaskan hal ini seperti helm yang digunakan pelanggan memiliki bau yang tidak enak sehingga menimbulkan ketidaknyamanan bagi pelanggan pada saat pengantaran. Kendala yang lain yaitu kurangnya respon yang cepat tanggap untuk menggambil pelanggan yang tujuan jarak jauh. hal ini menimbulkan pelanggan kecewa dan memutuskan mencari driver lain yang merespon baik. Kejadian seperti ini yang menyebabkan ketidakpuasan pelanggan terhadap pelayanan yang diberikan oleh driver ojek online (OJOL) GrabBike di Kota Tegal. 
Dalam hal ini kepuasan pelanggan juga belum maksimal yang ditandai dengan adanya keluhan yang dirasakan oleh pelanggan seperti seringnya aplikasi meminta untuk di upgrade kembali sehingga membuat pelanggan merasa terganggu saat sedang terburu-buru apalagi jika pelanggan tidak mempunyai cukup kuota untuk memperbarui aplikasi grab tersebut. Kendala lain yaitu keterlambatan driver dalam melakukan penjemputan pelanggan sehingga mereka memerlukan waktu untuk menunggu. Pentingnya kualitas pelayanan dalam menjaga dan mempertahankan kepuasan pelanggan transportasi daring, maka perlu dikembangkan penelitian mengenai Studi tentang kualitas pelayanan Ojek Online khususnya Grabbike dan pengaruhnya terhadap kepuasan pelanggan yang berada di wilayah di Kota Tegal.

\section{A. Kualitas Pelayanan}

Strategi yang dilakukan perusahaan agar dapat meningkatkan usahanya antara lain dengan memberikan pelayanan memuaskan (excelent service) dan berkualitas kepada pelanggan. Segala bentuk pelayanan yang disajikan sebaiknya sesuai dengan ekspektasi pelanggan, karena kualitas menjadi salah ukuran pelanggan mencapai kepuasan bagi pelanggan, maka perusahaan harus mampu menciptakan apa yang di butuhkan pelanggan.

Yamit (2018:8) mendefinisikan kualitas sebagai suatu keadaan yang terpenuhi dan sesuai dengan tujuan dan harapan yang berhubungan pada proses, produk, jasa, dan lingkungan yang kondusif. Kualitas atau mutu merupakan suatu penilaian dari pelanggan berdasarkan persepsi terhadap suatu jasa tertentu yang telah terpenuhi keinginannya. Algifari, (2016:2) mendefinisikan pelayanan adalah penyediaan layanan pada konsumen atau pemakai. Sedangkan menurut. Yamit (2018:22) mendefinisikan kualitas pelayanan adalah suatu tingkatan yang diberikan pada pelanggan kepada layanan yang diberikan.. Kualitas pelayanan merupakan cara terbaik yang konsisten untuk dapat mempertemukan harapan pelanggan dan sistem kinerja cara pelayanannya. Sedangkan menurut Kualitas pelayanan sebagai sumber keunggulan kompetitif berperan untuk memperbaiki pelayanan kepada pelanggan dan menghindari masalah-masalah potensial yang muncul maka dalam sebuah penyajian yang di sediakan oleh perusahaan harus dapat memenuhi keinginan pelanggan sehingga akan mendatangkan rasa puas pada diri pelanggan.

Pernyataan lain juga disampaikan oleh Kasmir (2016:298), customer service adalah suatu kegiatan untuk memberikan layanan yang maksimal agar pelanggan merasa terpenuhi harapan dan keinginannya.. Pelayanan sangat penting peranannya bagi keberhasilan organisasi bisnis maupun swasta tentunya untuk mendapatkan keuntungan dengan cara memberikan layanan yang baik kepada pelanggan. Kesimpulannya pelayanan yang terbaik akan menghasilkan hasil yang baik dan sangat diterima oleh pelanggan apabila dilaksanakan dengan konsisten dan profesional.

\section{B. Kepuasan Pelanggan}

Kepuasan merupakan perasaan seseorang setelah membandingkan harapan dengan apa yang diperoleh terhadap suatu produk. Hal tersebut sejalan dengan pendapat Priansa (2017:196) dan Sangadji (2013:180) yang mengartikan kepuasan sebagai rasa bahagia atau ketidakpuasan seseorang yang muncul setelah membandingkan antara hasil produk yang dipikirkan terhadap hasil yang diperoleh, apakah produk tersebut telah memenuhi kebutuhan/harapan mereka atau belum. Menurut Wijayanti (2017:186) kepuasan pelanggan adalah persepsi 
pelanggan bahwa tujuannya adalah dengan menggunakan layanan atau produk tersebut keinginan tercapai dengan baik. Berdasarkan berbagai pendapat diatas dapat disimpulkan bahwa kepuasan pelanggan adalah persepsi dan perasaan konsumen setelah menggunakan layanan yang diberikan memberikan kinerja memuaskan atau tidak, timbul setelah membandingkan antara ekspektasi pelanggan terhadap kinerja produk tersebut setelah memakainya.

\section{METODE PENELITIAN}

Metode penelitian yang digunakan pada penelitian ini dengan pendekatan deskriptif kuantitatif. Penelitian dilakukan di kantor Grab Kota Tegal dengan subjek seluruh pelanggan yang menggunakan jasa transportasi ojek online (OJOL) GrabBike dengan jumlah populasi sebesar 1000 pelanggan dalam jangka waktu satu minggu pada awal bulan Maret. Pengambilan sampel menggunakan teknik insidental sampling memakai rumus Slovin diperoleh populasi
1000 menjadi 100 pelanggan. Sumber data yang digunakan dalam penelitian ini yaitu sumber data primer dan sumber data sekunder. Sumber data primer adalah sumber data yang langsung memberikan data kepada pengumpul data seperti memberikan angket kepada responden untuk memeroleh informasi studi tentang kualitas pelayanan ojek online Grabbike pengaruhnya terhadap kepuasan pelanggan di Kota Tegal.

\section{HASIL DAN PEMBAHASAN} Analisis Data

\section{Uji Validitas Instrumen}

Hasil uji validitas instrumen angket penelitian ini menggunakan uji coba 20 pelanggan dan taraf signifikan 5\% untuk uji coba $(N)=20$ adalah 0,444. Dikatakan valid apabila $r_{\text {hitung }}>$, sedangkan dikatakan tidak valid apabila hasil $r_{\text {hitung }}>$. Adapun rekapitulasi uji validitas 12 butir angket ditunjukkan pada tabel sebagai berikut:

\section{Rekapitulasi Hasil validitas 12 Butir Soal Angket Variabel Kualitas Pelayanan (X)}

\begin{tabular}{cccc}
\hline No Butir Soal & $\begin{array}{c}\text { Koefisien Korelasi } \\
\text { (r hitung) }\end{array}$ & $\begin{array}{c}\mathrm{r} \text { tabel } \\
\text { pada N=20 }\end{array}$ & Kesimpulan \\
\hline 1 & 0,527 & 0,444 & Valid \\
2 & 0,477 & 0,444 & Valid \\
3 & 0,541 & 0,444 & Valid \\
4 & 0,517 & 0,444 & Valid \\
5 & 0,661 & 0,444 & Valid \\
6 & 0,507 & 0,444 & Valid \\
7 & 0,593 & 0,444 & Valid \\
8 & 0,487 & 0,444 & Valid \\
9 & 0,570 & 0,444 & Valid \\
10 & 0,631 & 0,444 & Valid \\
11 & 0,610 & 0,444 & Valid \\
12 & 0,472 & 0,444 & Valid \\
\hline
\end{tabular}

Sumber: data primer diolah, Mei 2019 


\section{Rekapitulasi Hasil Uji validitas 12 Butir Soal Angket Variabel}

\section{Kepuasan Pelanggan (Y)}

\begin{tabular}{cccc}
\hline $\begin{array}{c}\text { No Butir } \\
\text { Soal }\end{array}$ & $\begin{array}{c}\text { Koefisien Korelasi } \\
\text { (r hitung) }\end{array}$ & $\begin{array}{c}\mathrm{r} \text { tabel } \\
\text { pada N=20 }\end{array}$ & Kesimpulan \\
\hline 1 & 0,617 & 0,444 & Valid \\
2 & 0,660 & 0,444 & Valid \\
3 & 0,521 & 0,444 & Valid \\
4 & 0,508 & 0,444 & Valid \\
5 & 0,544 & 0,444 & Valid \\
6 & 0,580 & 0,444 & Valid \\
7 & 0,528 & 0,444 & Valid \\
8 & 0,461 & 0,444 & Valid \\
9 & 0,516 & 0,444 & Valid \\
10 & 0,483 & 0,444 & Valid \\
11 & 0,532 & 0,444 & Valid \\
12 & 0,485 & 0,444 & Valid \\
\hline
\end{tabular}

Sumber: data primer diolah, Mei 2019

Dari hasil analisa validitas yang dilakukan untuk angket kualitas pelayanan (X) dan kepuasan pelanggan (Y) bahwa semua instrumen menghasilkan nilai rhitung > rtabel maka seluruh butir soal dinyatakan valid.

\section{Uji Reliabilitas Instrumen}

Hasil uji reliabilitas instrumen angket penelitian ini menggunakan jumlah butir soal sebanyak 12 untuk instrumen kualitas pelayanan dan 12 butir soal untuk instrumen kepuasan pelanggan. Suatu variabel dikatakan reliabel apabila :

Nilai Alpha Cronbach $>0,70=$ reliabel

Nilai Alpha Cronbach $<0,70=$ tidak reliabel. Ghozali(2011:48).

Sebaran angket dibagikan kepada pelanggan Grabbike sebagai responden dengan hasil perhitungan pada uji reliabilitas pada variabel kualitas pelayanan (X) dan kepuasan pelanggan (Y) adalah sebagai berikut:

\section{Hasil Uji Reliabilitas Variabel (X)}

Reliability Statistics

\begin{tabular}{cc}
\hline Cronbach's Alpha & N of Items \\
\hline .790 & 12 \\
\hline
\end{tabular}

Hasil Uji Reliabilitas Variabel Variabel (Y) Reliability Statistics

\begin{tabular}{cc}
\hline Cronbach's Alpha & N of Items \\
\hline .762 & 12 \\
\hline
\end{tabular}

Dari tabel diatas diketahui bahwa variabel kualitas pelayanan (X) sebesar 0,790 dan kepuasan pelanggan (Y) sebesar 0,762 maka dapat dikatakan reliabel untuk variabel kualitas pelayanan dan kepuasan pelanggan.

\section{Analisis Deskriptif}

Berdasarkan penelitian pada perusahaan ojek online (OJOL) GrabBike di Kota Tegal masing-masing analisis deskriptif adalah sebagai berikut: 
Kualitas Pelayanan (X)

Deskriptif Frekuensi Data Kualitas Pelayanan

\begin{tabular}{cccccc}
\hline No & Kategori & $\begin{array}{c}\text { Rentang } \\
\text { Skor }\end{array}$ & Frek. & Presentase & Mean \\
\hline 1 & Sangat Baik & $42-48$ & 13 & $13 \%$ & \\
2 & Baik & $37-41$ & 30 & $30 \%$ & \\
3 & Cukup Baik & $32-36$ & 33 & $33 \%$ & 35,54 \\
4 & Kurang Baik & $27-31$ & 19 & $19 \%$ & \\
5 & Cukup Buruk & $22-26$ & 5 & $5 \%$ & \\
6 & Buruk & $17-21$ & - & - & \\
7 & Sangat Buruk & $12-16$ & - & - & \\
\multicolumn{7}{c}{ Jumlah } & & $\mathbf{1 0 0}$ & $\mathbf{1 0 0 \%}$ & \\
\hline
\end{tabular}

Berdasarkan perhitungan data, menunjukkan sebagian besar pelanggan menilai cukup baik kualitas pelayanan GrabBike di Kota Tegal. Hasil tersebut dibuktikan dengan nilai rata-rata sebesar 35,54 yang termasuk dalam kategori cukup baik disamping itu kualitas pelayanan yang masuk kategori cukup baik sebesar 33\%.

Kepuasan Pelanggan (Y)

\begin{tabular}{lccccc}
\hline No & Kategori & $\begin{array}{c}\text { Rentang } \\
\text { Skor }\end{array}$ & Frek. & Presentase & Mean \\
\hline 1 & Sangat Tinggi & $42-48$ & 5 & $5 \%$ & \\
2 & Tinggi & $37-41$ & 31 & $31 \%$ & \\
3 & Cukup Tinggi & $32-36$ & 37 & $37 \%$ & \\
4 & Kurang Tinggi & $27-31$ & 24 & $24 \%$ & 34,57 \\
5 & Cukup Rendah & $22-26$ & 3 & $3 \%$ & \\
6 & Rendah & $17-21$ & - & - & \\
7 & Sangat Rendah & $12-16$ & - & - & \\
Jumlah & & $\mathbf{1 0 0}$ & $\mathbf{1 0 0 \%}$ & \\
\hline
\end{tabular}

Berdasarkan perhitungan data, menunjukkan sebagian besar pelanggan menilai kualitas pelayanan cukup tinggi. Hasil tersebut dibuktikan dengan nilai rata-rata sebesar 34,57 yang termasuk dalam kategori cukup tinggi, disamping itu kepuasan pelanggan yang masuk kategori cukup tinggi sebesar $37 \%$.

Analisis Regresi Linear Sederhana

Hasil Analisis Regresi Linear Sederhana Kualitas Pelayanan Terhadap Kepuasan Pelanggan

Coefficients $^{\mathrm{a}}$

\begin{tabular}{|c|c|c|c|c|c|c|}
\hline & \multirow[b]{2}{*}{ Model } & \multicolumn{2}{|c|}{ Unstandardized Coefficients } & \multicolumn{2}{|l|}{$\begin{array}{l}\text { Standardized } \\
\text { Coefficients }\end{array}$} & \multirow[b]{2}{*}{ Sig. } \\
\hline & & $\mathrm{B}$ & Std. Error & Beta & $\mathrm{T}$ & \\
\hline \multirow[t]{2}{*}{1} & (Constant) & 16.078 & 2.550 & & 6.304 & .000 \\
\hline & $\begin{array}{l}\text { Kualitas } \\
\text { Pelayanan }\end{array}$ & .520 & .071 & .595 & 7.326 & .000 \\
\hline
\end{tabular}

a. Dependent Variable: Kepuasan Konsumen 
Berdasarkan hasil perhitungan analisis regresi dapat diketahui bahwa kualitas pelayanan berpengaruh positif dan signifikan terhadap kepuasan pelanggan. Hasil perhitungan regresi menunjukkan $\mathrm{Y}=16,078+0,520 \mathrm{X}$. Dari hasil persamaan tersebut dapat dijelaskan bahwa apabila kualitas pelayanan dinaikan sebesar 1\% maka akan mempengaruhi kepuasan pelanggan sebesar 0,520. Sedangkan nilai signifikan 0,000 . Suatu data dapat diterima jika nilai signifikan $<0,05$ karena $0,000<0,05$. Maka dapat disimpulkan bahwa variabel Kualitas Pelayanan berpengaruh signifikan terhadap variabel Kepuasan Pelanggan pada ojek online (OJOL) GrabBike di Kota Tegal.

\section{PENUTUP}

\section{Simpulan}

Berdasarkan hasil penelitian dan pembahasan, maka dapat diambil simpulan bahwa terdapat pengaruh yang signifikan antara kualitas pelayanan terhadap kepuasan pelanggan pada ojek online (OJOL) GrabBike di Kota Tegal. Pengaruh tersebut terbukti dari hasil perhitungan statistik regresi linear sederhana dengan persamaan regresi diperoleh $\mathrm{Y}=16,078+0,520 \mathrm{X}$ yaitu setiap penambahan $1 \%$ nilai kualitas pelayanan, maka nilai kepuasan pelanggan bertambah sebesar 0,520 sedangkan nilai koefisien signifikansi dari variabel kualitas pelayanan sebesar 0,000. Suatu penelitian dapat dipercaya atau diandalkan jika nilai signifikansi $<0,05$, karena $0,000<0,05$ maka dapat dinyatakan ada pengaruh yang signifikan antara kualitas pelayanan terhadap kepuasan pelanggan pada ojek online (OJOL) GrabBike di Kota Tegal. Berarti Ha diterima dan $\mathrm{H} 0$ ditolak.

\section{Saran}

Saran yang diberikan kepada perusahaan Grab adalah dengan meningkatkan kualitas pelayanan terutama pelayanan pada ojek online (OJOL) GrabBike serta untuk lebih meningkatkan kenyamanan pelanggan dan diharapkan melakukan evaluasi mengenai pelayanan guna membuat kepercayaan pelanggan terhadap kualitas layanan yang diberikan.

\section{DAFTAR PUSTAKA}

Algifari. (2016). Mengukur Kualitas Layanan dengan Indeks Kepuasan, Metode Importance-Performance Analysis (IPA), dan Metode Kuno. BPFEYOGYAKARTA

Arikunto, Suharsimi. (2013). Prosedur Penelitian Suatu Pendekatan Pratik. Jakarta. PT Rineka Cipta.

Ghozali, Imam. (2011). Aplikasi Analisis Multivariate dengan Program IBM SPSS 19. Semarang: Badan Penerbit Universitas Diponegoro

Kasmir. (2016). Kewirausahaan. Jakarta. PT Raja Grafindo Persada.

Adam, Muhammad. (2015). Manajemen Pemasaran Jasa. Bandung: Alfabeta.

Priansa, Donni Juni. (2017). Perilaku Pelanggan dalam Persaingan Bisnis kontemporer. Bandung: Alfabeta.

Sangadji, Sopiah. (2013). Perilaku Pelanggan Pendekatan Praktis. Yogyakarta:Andi Offset.

Sugiyono. (2017). Metode Penelitian Pendidikan Pendekatan Kuantitatif Kualitatifdan R\&D. Bandung:Alfabet.

Wijayanti, Titik. (2017). Marketing Plan Dalam Bisnis. Jakarta: Penerbit Gramedia.

Yamit, Zulian. (2018). Manajemen Kualitas Produk \& Jasa. Yogyakarta: Ekonosia.

Yanto. (2016). Statistika Inferensial untuk Penelitian Minitab. Yogyakarta: Andi Offset. 